\title{
How Does the Nomination of a Project Manager Affect Project Success?
}

\author{
Yehualashet Getahun Ayele \\ School of Commerce, Addis Ababa University, PO box 1176, Addis Ababa University, Ethiopia
}

\begin{abstract}
There have been only few empirical studies that have attempted to explore the relationship between the nomination of a project manager (PM) and project success. Thus, as the researcher's attempt to fill this knowledge gap, this research was designed to examine the effect of project manager nomination on project success. Because the primary role of the project manager (PM) is to work with senior management to ensure that they provide resources and support and take care of team issues that might negatively influence the team's productivity, the starring role of a PM is indispensable. Most of all, given limited project resources, the PM is responsible for making trade-off decisions between project budget, project schedule, and project scope that are needed to ensure project success. Hence, the project manager (PM) is the glue holding the project together and the mover and shaker spurring it on. In brief, the project manager is an important contributor to project success. However, surprisingly enough, most company executives do not even acknowledge the significant role a project manager plays to project success; and hence the assignment of a PM to a project is not their concern as such. This, as a result, leads to frequent project failures even without knowing the genuine cause of the failure. As any rational thinker can imagine, if the true problem (cause of the failure) is not known, a curing solution is unlikely to be applied. Yet many efforts have been spent in recent decades to enhance the project management success. But results are still highly unsatisfactory, perhaps because the true problem is not yet identified - nomination of the wrong PM. Briefly, disregarding the effect of project manager nomination on project success and expecting successful project conclusion is like doing the same mistake again and again and expecting a different result. Accordingly, since the success or failure of a project predominantly depends on who manages it, nominating a project manager to a project is among the most important decisions in project management. With the right nomination, a project manager is more likely to coordinate the human and material resources of the project to its success than otherwise. However, the nomination process should neither be a procedural undertaking nor too late to lead the project on the right track. Likewise, one of the major findings of this research supports the idea that the nomination of the right project manager to the right project at the right time is a strategic decision that affects key project parameters. Nevertheless, regardless of the potential effect of the nomination decision on the success of a project, nominating the right project manager to a project is often very challenging. To sum up, the nomination of a project manager to a project is the most phenomenal decision to be made by the senior management of an organization as early as possible. The early nomination enables the project manager to get involved in the project development endeavours beginning from its inception, and helps him/her to fully comprehend the project objective and any other commitment that might have been assumed in the planning stage of the project or even before. Finally, this research also uncovered that the more the organizational context, the strategic importance of the project, the competency of the project manager, the specific requirements of the project, and the availability of the project manager (when the PM to be assigned is to manage multiple projects simultaneously) are considered during project manager nomination, the superior the nomination will be.
\end{abstract}

Keywords: Nomination, Perception, Project Manager, Project Success

DOI: $10.7176 / \mathrm{EJBM} / 12-22-01$

Publication date:August $31^{\text {st }} 2020$

\section{1) Knowledge Gap}

The nomination of a project manager (PM) is one of the most bewildering subjects in the study of project management. Some authorities in the area perceive the nomination of a project manager (PM) to a project as the first, and perhaps the most important, success factor; while others think it just as a procedural undertaking. For some project management professionals, the project manager is the central figure in accomplishing projects successfully. For these authorities, the salient factor in successful project management, with the role of project manager being so central, is the nomination of the PM; and without it there would not even be project management. Thus, the project manager (PM) is the glue holding the project together and the mover and shaker spurring it on. Because the primary role of the project manager is to work with management to ensure that they provide resources and support as well as take care of team issues that might negatively influence the team's productivity, the starring role of a PM is indispensable. Besides, the project manager is also responsible for decision-making in order to control risk and deal with uncertainties. They also argue that as the success or failure of a project predominantly depends on the competency of the project manager, the nomination of a PM should be given the highest possible attention as it perhaps concludes the fate of the project. Accordingly, it has been argued by many project experts 
that a project team is only as good as the project manager; and a project fails when the senior management fails to nominate the right project manager for the right project at the right time.

Others, on the other hand, argue that a project manager is just a mere member of the project team whose mere determination \& competency cannot boost or undermine project success. They say, in most cases, a project manager is a senior project expert struggling to execute other's plan even when he/she doesn't fully comprehend the project plan he/she is referring to. Every so often this is true as a PM is nominated after the project plan is finalized. In view of this, it has been argued by Lockyer and Gordon (1996) that a project manager should be nominated as early as possible in any kind of project, ideally in the planning stage. Yet this is usually unrealistic for many organizations as part of their attempt to minimize payment budget. However, this normally causes problems because the project manager will not be able to wholly understand the full commitment assumed in the beginning (particularly planning) stage of the project. This, in turn, undermines the role of the PM as he/she is not in any better position to lead the execution of the project plan (and most importantly to own it) than any of the other project team members. This, again, makes the nomination of a project manager just a procedural undertaking which is less likely to add anything unto the performance of the project. Thus, they argue, the nomination of a project manager is not as important as it is perceived by many project experts.

\section{2) Background of the Study}

The nomination of a project manager to a project is the most phenomenal decision to be made by the senior management of an organization once a project is selected. This should be made as early as possible to enable the project manager get involved in the project development endeavors beginning from its inception. This, in turn, helps the project manager to fully comprehend the project objective and any other commitment that might have been assumed in the planning stage of the project or even before. This makes him/her to own the project, and have a clear idea of project undertakings. As anyone can imagine, this simplifies the job of the project manager (and increases the rate of project success) as he/she will be executing his/her own plan for which he/she already has a clear picture of it in mind. Altogether, the nomination of a project manager to a project is considered as one of the ground-breaking project decisions since it influences the performance of the project in particular and that of the owner organization in general. In short, literatures on the influence of project manager nomination argue that PM nomination influences both project and organizational performances.

Since the success or failure of a project predominantly depends on who manages it, nominating a project manager to a project is among the most important decisions in project management. Therefore, the assignment of a project manager should be given the attention it deserves so that the assignment enhances the achievement of the project's strategic objectives. It is obvious that the right Project Manager (PM) endorses a project's success. Hence, the right PM is an imperative instrument through which organizations achieve competitive advantage. Furthermore, the right PM can also carry a project through a period of unpredicted crisis and ensure its future success. Hence, an effective nomination of a project manager is crucial to the success of an organization.

When assigning a Project Manager to a project both the project context and the competency of the prospective PM should be taken into account. If the prospective project manager's competencies match with the project requirements, then the project manager is likely to perform better than if there was no match. According to the PMBOK Guide, understanding and applying the tools and techniques of project management is not enough for success. The PM must also be a person who can shoulder responsibility as he/she is responsible to the project team, to senior management, to the client, and to anyone else who may have a stake in the project's performance or its outcomes. After all, it is the Project Manager's job to make sure that the project is properly implemented and successfully completed. This demands a project manager possessing a wide variety of skills related to the standard objectives of project completion within a set of specifications under time, cost, and quality constraints. Thus, the PM must be skilled at negotiation, conflict resolution, and influencing decision making.

The PM is responsible for providing whatever is genuinely wanted (material or human resource) by the project team to bring the project plan to reality. He/she is also responsible for exercising human and material management, leadership, and dealing with stumbling blocks that obstruct the project's progress. Most of all, the PM is responsible for making the trade-offs between project budget, project schedule, and project scope that are needed to ensure project success.

More often than not, successful PMs have remarkable administrative and technical integrity, impressive interpersonal conflict management skill, and prodigious communication dexterity to get help from senior management when needed. In addition, the PM should be a leader, and adopt a participatory management style that may have to be modified depending on the level of technological sophistication and uncertainty involved in the project. Besides, he/she needs to be willing to listen to others' opinion and be open to new ways of doing things. Another critical project management skill is the ability to direct the project in the best interest of both project sponsors and project clients with the minimum possible cost. 


\section{3) Statement of the Problem}

There is no doubt that the nomination of the right project manager to a project has multiple implications to organizational effectiveness and efficiency. Likewise, as project resources are limited, their wise use is not debatable. Previous researches carried out in the area recognized that having the right project manager for a project can significantly contribute to its success. With the right project manager, a project is more likely to be completed within predetermined project constraints. On the contrary, failing to assign the right project manager to a project is likely to lead to project failure. Generally, as the project manager is the key personnel in project management, the nomination of a project manager to a project is a critical success factor.

However, company executives often nominate project managers without having a strong background in projects themselves. This makes the assignment of the right project manager (PM) to a project hardly possible. As a result, more often than not, the wrong PM is assigned to most projects. This failure to assign the right PM leads to poor project management; and eventually failure of the project. Accordingly, many project failures can be traced to bad choices in this area. Yet this could have been avoided had project managers been assigned with knowledge: to the minimum considering the match between their competency and the project requirements. In this regard, experienced company executives recommend that at least the company's organizational structure, the nature of the project under consideration, and the qualities of the project manager to be assigned should be considered when nominating a PM to a project. Studies also indicate that there are projects where so many unforeseen obstacles and problems arose that failure could be expected but the project succeeds because of the leadership and other qualities of the project manager. Accordingly, an experienced project manager helps avoid success barriers by ensuring the project is organized for success. Thus, a little bit of pre-planning, clarification of roles and expectations, and team spirit building roles played by a PM can contribute marvelously to evident project success.

The right project manager brings a wide variety of experience and knowledge based on thousands of hours of successful and challenging projects. If a project team implements a project in a new domain or a new business process, adding a project manager with the apt experience will be instrumental to the project's success. Otherwise, company executives will bear the cost of experiencing those project settings for the first time around!

The project manager's post lies at the center of the principles of project management. Given the project manager's ultimate responsibility for the project's outcome, a PM should be able to focus on issues in detail while at the same time keeping a clear view of the project as a whole. This ability to focus within the overview ensures that people and resources are obtained and utilized in an integrated way, including reorganizing them to overcome problems and difficulties that will inevitably arise from time to time, in order to accomplish the project's goals and objectives. For this effect, the project manager occupies a central position in managing the various people and organizations involved in the project much like a spider at the center of a web does.

With the indispensable role of project managers to project success, the nomination of a project manager to a project becomes a fundamental managerial decision. With the right nomination, a project manager is more likely to coordinate the human and material resources of the project to its success. Nevertheless, regardless of the potential effect of the nomination decision on the success of a project, nominating the right project manager to a project can be very challenging.

A PM has four most important duties: the acquisition of material and human resources, dealing with the difficulties that arise during the course of the project, and exercising the leadership needed to bring the project to a successful conclusion, and making the trade- offs necessary to do so.

Since projects are performed in a set of project constraints (such as project cost, schedule, and scope), given limitations of project resources, the PM may be forced to meet one of the constraints at the expense of one or more of the remaining constraints. In this case, the PM is the principal player in making trade- offs between the constraints. Therefore, the PM makes the decision of which of the project constraints has higher priority than the others. This decision is made based on many factors including (but not limited to) the project context, the client's interest, and the parent organization's state of affairs. If, for example, cost is more important than time for a given project, the PM will allow the project to be late rather than incur added costs. If a project has successfully completed most of its specifications, and if the client is willing, both time and cost may be saved by not pursuing some remaining specifications. Altogether, the trade-off decision between project resources (may be called project constraints) is principally made by the PM thereby making him/her the key project personnel.

Likewise, when the same PM manages two or more projects of the same company, another type of trade- off occurs between the projects. This results in a situation wherein two or more projects may compete for access to the same resources. But the upshot is that added progress on one project may be traded off for less progress on another. If a single PM has two projects in the same part of the project life cycle and makes such a trade- off, it does not matter which project wins, the PM will lose. As a solution to this problem, project experts strongly recommend that any PM managing two or more projects do everything possible to avoid this problem by making sure that the projects are in different phases of their life cycles.

On the other side of the line, since no two projects are identical to one another, every project brings new experiences to the project team. No matter how experienced the team is, projects introduce new processes, systems, 
and organizational changes that the project team hasn't experienced before. Hence, some company executives argue that as projects are unique, even highly experienced project managers are equally unaware to new project settings as every other member of the project team. Accordingly, they continue their argument, since every project team member will be facing project contexts for the first time (because projects are unique); no single member of the project team is better fit to lead the project than other members. According to these executives, leadership isn't reserved just for few project managers as each team member is expected to apply situational leadership when called upon. In conclusion, they argue that the nomination of a PM is not more than a procedural undertaking as every member of the project team is equally likely to lead the project at the same level of success as experienced PMs.

In contrast, experiences show that when projects go off track, most company executives return to the fundamentals of managing cost, schedule, scope, and quality and choose to fix the problem by assigning experienced PMs. When executive stakeholders finally recognize the project needs professional help, it is often too late to rescue the project and maintain the original project objectives. Nominating a project manager in the early stage of a project mitigates the risk of cost and schedule overruns. Nevertheless, assigning a project manager doesn't mean guaranteed success. However, it guarantees communication of project issues, delays, and solutions based on years of experience before it is too late to correct. Here, it is worth noting that it is better to invest in the fundamentals (and assign a PM) from the beginning rather than paying expensive consultants to turn around a project and install those fundamentals eventually. In brief, it is cheaper to invest in the project management function and nominate a PM now rather than later in the project.

However, most company executives are hesitant to nominate the right PM at the right time for the right project. Accordingly, despite the significant role of the project manager, quite large number of project management experiences show that the nomination of a PM to a project is one of the most disregarded project management undertakings. Surprisingly enough, researches in the area also indicate that most project failures are attributed to acts of wrong PM nomination. These researches also disclosed that it is not only the nomination of the PM that matters but also the timing of the nomination.

\section{4) Basic Research Questions}

As noted earlier, there have been only few empirical studies that have attempted to explore the relationship between nomination of a project manager and project success in the wide context of project management. Thus, as the researcher's attempt to fill this research gap and discover how the assignment of a PM affects project success, this research ultimately answers the following six basic research questions.

A) How do you perceive the nomination of a project manager?

B) What are the principal roles of a project manager?

C) What are the qualities of a good project manager?

D) What are the salient criteria for PM nomination?

E) At which stage of the project life cycle should a project manager be nominated?

F) What is the importance of a PM to project success?

\section{5) Research Objectives}

\section{1) General Objective}

The main objective of this research was to examine the effect of project manager nomination on project success.

\section{2) Specific Objectives}

Since the objective of this research was to investigate the impact of project manager nomination on the success of projects in different project settings, this research profoundly strived:

a) to inspect how the nomination of a project manager is perceived by different stakeholders;

b) to ascertain the principal roles of a project manager;

c) to identify the qualities of a good project manager;

d) to discover the salient criteria for PM nomination;

e) to determine the most convenient stage of the project life cycle to nominate a project manager; and

f) to investigate the impact of PM nomination on project success.

\section{6) Significance of the Study}

There is no doubt that company executives want their projects to succeed. But projects do not succeed only because company executives wanted them to succeed. The only place where success comes before work is in the dictionary. Yet, in the real world, success is the outcome of a work done. Therefore, company executives should first do their assignment for their projects to succeed. Hence, the nomination of a project manager to a project is the least company executives should do to get their project on the right track.

Experience has shown that the nomination of a project manager is a key appointment which can influence the 
success or failure of a project. As the single point of responsibility, the project manager integrates and coordinates all project resources, and guides the project team to successfully complete the project.

As projects grow in size and complexity, the ability to plan and control them has become a key project management function. This role is primarily played by the project manager. The project manager should also be able to develop a fully integrated information and control system to plan, implement, monitor and control large amounts of data, quickly and accurately to facilitate the problem solving and decision-making process. To achieve these goals company executives need to be able to assign the right project manager.

However, surprisingly enough, researches indicate that most company executives do not even acknowledge the significant role a project manager plays to project success; and hence the assignment of a PM to a project is not their concern as such. This, in turn, leads to frequent project failures even without knowing the genuine cause of the failure. If the true problem (cause of the failure) is not known, a curing solution is unlikely to be applied. What a gap! It is this gap that this study wants to bridge.

On the other hand, despite its importance, literature on project manager nomination is rather limited. In practice, with the resource constraints faced by a typical organization, making the appropriate PM nomination decisions can be challenging. This challenge is even more paramount in a setting where project managers lead multiple and concurrent projects. Thus, the researcher of this study believes that challenges of this kind can be overcome through responsible studies in the area. Therefore, this research looks forward to contribute to the PM nomination body of knowledge in project management. It also serves as an input for further detailed studies in the area.

\section{7) Research Methodology}

With the overriding objective of discovering the effect of project manager nomination on project success, mixed (fundamentally qualitative) research approach was adopted as an alternative method of carrying out the research. Meanwhile, in an attempt to answer the aforementioned research questions, a cross-sectional survey design was adopted. By means of a survey involving 539 project management professionals working on different projects at different levels, it was possible to establish a map to analyze the theme of the effect of nominating a project manager to a project. The study involved company executives and other project stakeholders from seven sectors of the economy that are classified into three types of projects, according to their level of complexity.

Multiple data collection techniques including interview and structured questionnaire, among others, were used to collect data. Therefore, to carry out this study both primary and secondary data sources were used. Review of selected literatures on project manager nomination was carried out in an attempt to appreciate the issue theoretically and to identify existing gaps in this area of knowledge. Likewise, company executives, project managers and other project team members were also consulted to get their insight into the subject.

Furthermore, the sampling technique of the research was nonprobability sampling. Therefore, both the sample units (which were projects) and the participants were chosen by their ease of access and availability to respond to the study. Despite using a non-probability sample, the researcher tried to meet the necessary requirements for a multivariate analysis.

In addition, to ensure the best data quality, all completed questionnaires were checked for integrity, accuracy, relevance and completeness of the data. Hence, all questionnaires not meeting these criteria were also rejected. Finally, the reliability of the data was checked using Cronbach's Alpha tests, which rendered a value of over 0.874 in each group of projects.

\section{8) Major Research Findings}

As contemporary companies have begun to recognize projects as critical to their success, more and more of them have embraced project management as an improvement tool and a key strategy for remaining competitive in today's highly competitive business environment. Now, it has come to be common knowledge by most company executives that project management is a strategic importance. Project management enlightens company executives and provides them a powerful set of tools that improves their ability to plan, implement, and manage activities to accomplish specific company objectives. But project management is more than just a set of tools; it is a resultsoriented management style that places a premium on building collaborative relationships among a diverse cast of characters. Yet the full benefits of project management can only be harvested if company executives pay due attention to the process of nominating the right project managers to their projects.

In this regard, the data collected for the purpose of this research revealed that $81 \%$ of the respondents perceive the nomination of a project manager, at least in principle, as important strategic decision. More to the point, it was only $4 \%$ of the research participants who were found to perceive PM nomination as any other procedural undertaking. 


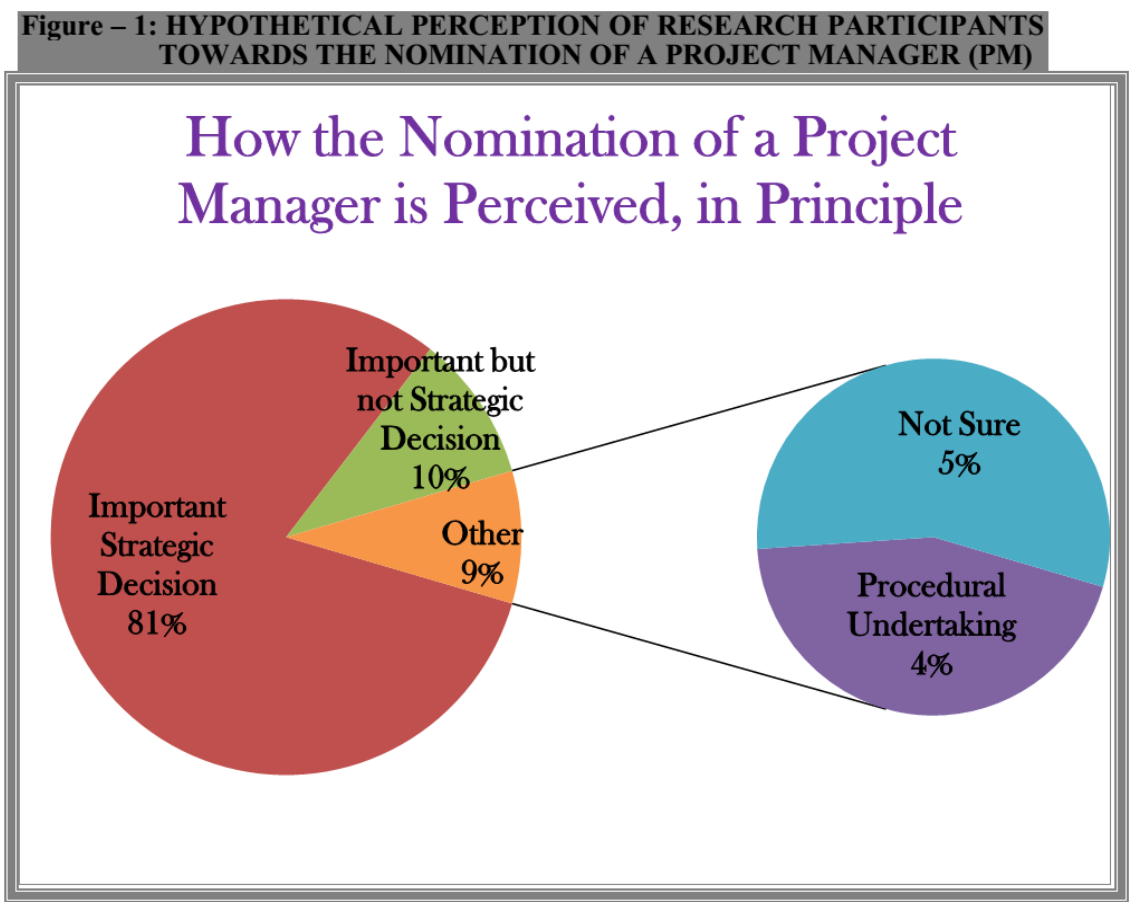

(Source: Own Survey)

Hence, the research data clearly revealed that there is harmony of thought among the research participants ( $91 \%$ of them) concerning how the nomination of a PM is important in project management.

On the other side of the spectrum, the same survey was made to find out the research participants' practical perception of PM nomination from their experience; and surprisingly enough only $17 \%$ of them claimed that they consider the nomination of Project Managers as important strategic decision.

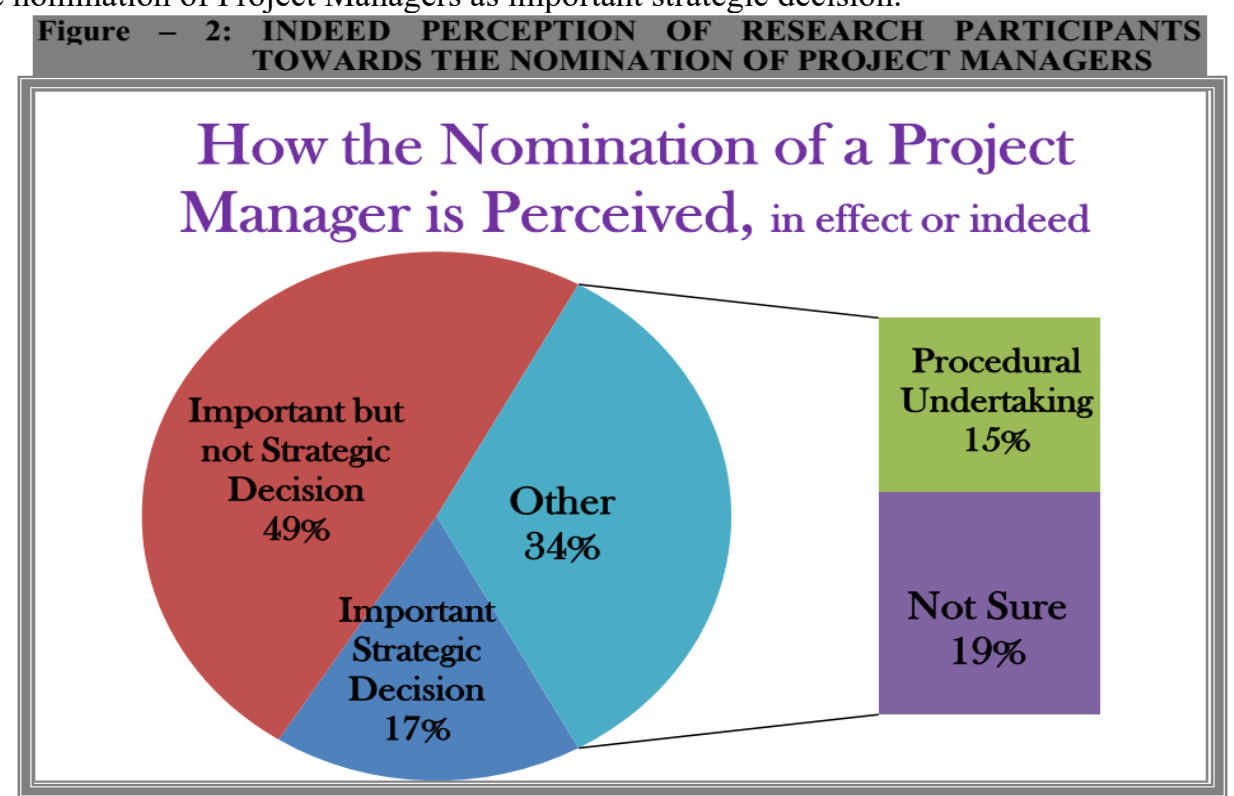

(Source: Own Survey)

As figure 1 and 2 above revealed, there is a huge discrepancy between the theoretical and practical perceptions of the participants involved in this research concerning the act of PM nomination. That is, they know that the nomination of a PM is an important decision; however; they disregard this important decision in their daily deeds. In other words, the actual value project professionals give to PM nomination clearly contradicts with the value that PM nomination has in their mind. This indicates that the importance of project manager nomination is well understood among project professionals but they are not living up to their understanding. This, in turn, has resulted in a gap between project experts' understandings and their deeds. Very shocking!!!

Furthermore, the study also identified the principal roles of a project manager. Monitoring project progress and executing the project plan were picked as the core roles of a project manager by $21 \%$ and $17 \%$ of the respondents respectively. Implementing a project management methodology was also designated by $11 \%$ of them. 


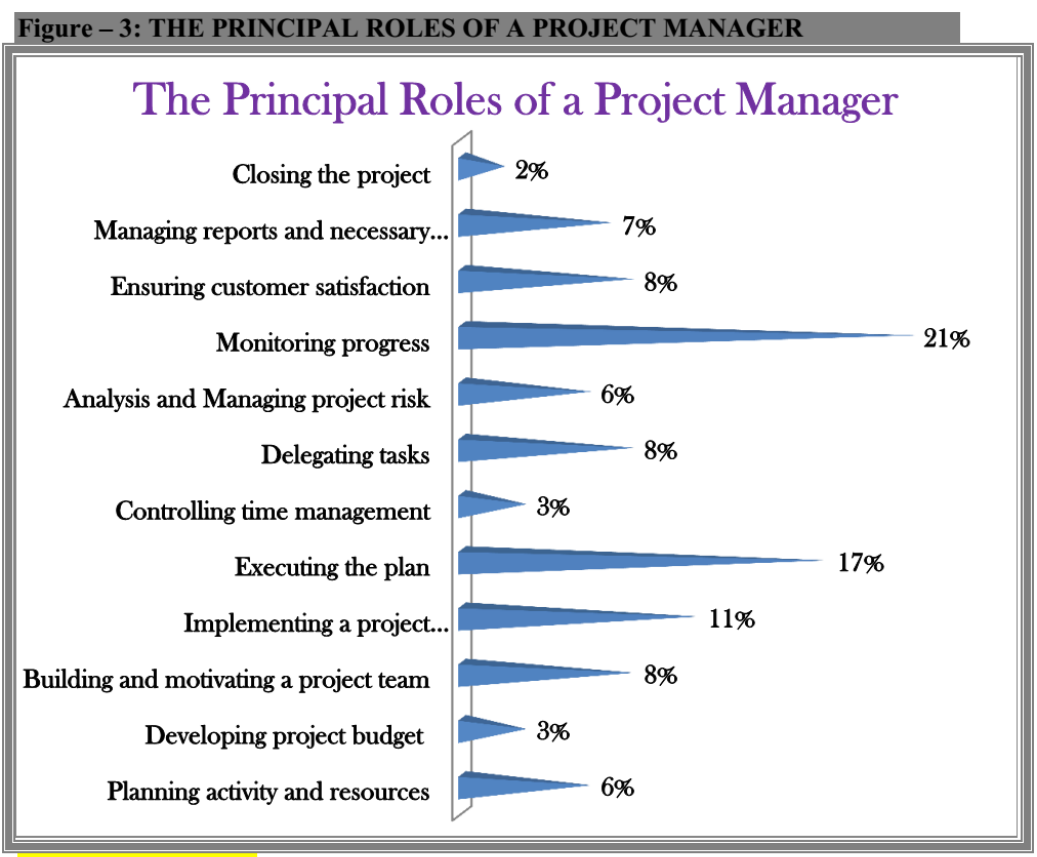

(Source: Own Survey)

Interviews with selected company executives also disclosed that given the above core roles of project managers (PMs), reliable PMs cut down on bureaucracy and steer their teams down a clear path to the final goal. This allows them to think about a project beyond the basic project setup they were given. Therefore, it is the project manager's job to influence company executives' decision making and direct their teams \& team members to the finish line. All things considered, the project's success or failure resets merely on the project manager's shoulders, and he/she is the one responsible for the end result of the project.

Nevertheless all project managers do not play the aforementioned roles of a project manager equally. Some project managers have great qualities which enable them to play the roles of a PM much better than other PMs do. Thus, to make the study complete, this study also ascertained the qualities of a good project manager. In this study, respondents were asked to list their five most important qualities of a good PM; then based on their response the table below is prepared to unveil top twelve qualities of a good PM.

\section{Table - 1: QUALITIES OF A GOOD PROJECT MANAGER}

\begin{tabular}{|l|l|r|r|}
\hline S/N & \multicolumn{1}{|c|}{ Qualities of a Good Project Manager } & \multicolumn{1}{c|}{ Frequency } & Percentage, \% \\
\hline $\mathbf{1}$ & Ability to share inspirational vision & $\mathbf{5 3 2}$ & $\mathbf{1 9 . 7 4}$ \\
\hline $\mathbf{2}$ & Communication skill & $\mathbf{4 5 8}$ & $\mathbf{1 6 . 9 9}$ \\
\hline $\mathbf{3}$ & Competency & $\mathbf{3 6 4}$ & $\mathbf{1 3 . 5 1}$ \\
\hline $\mathbf{4}$ & Integrity & $\mathbf{3 1 0}$ & $\mathbf{1 1 . 5 0}$ \\
\hline $\mathbf{5}$ & Empathy & $\mathbf{2 4 3}$ & $\mathbf{9 . 0 1}$ \\
\hline $\mathbf{6}$ & Enthusiasm & $\mathbf{2 0 2}$ & $\mathbf{7 . 5 0}$ \\
\hline $\mathbf{7}$ & Ability to delegate tasks & $\mathbf{1 3 5}$ & $\mathbf{5 . 0 1}$ \\
\hline $\mathbf{8}$ & Team-building skills & $\mathbf{1 2 8}$ & $\mathbf{4 . 7 5}$ \\
\hline $\mathbf{9}$ & Encourage and recognize valuable contributions & $\mathbf{1 2 1}$ & $\mathbf{4 . 4 9}$ \\
\hline $\mathbf{1 0}$ & Ability to work under pressure & $\mathbf{8 1}$ & $\mathbf{3 . 0 1}$ \\
\hline $\mathbf{1 1}$ & Problem solving skill & $\mathbf{6 7}$ & $\mathbf{2 . 4 9}$ \\
\hline $\mathbf{1 2}$ & Fully vested in success & $\mathbf{5 4}$ & $\mathbf{2 . 0 0}$ \\
\hline & & $\mathbf{5 3 9} \mathbf{X} \mathbf{5}=$ & $\mathbf{1 0 0 . 0 0 \%}$ \\
\hline
\end{tabular}

(Source: Own Survey)

*** Since 539 respondents were involved and each of them stated their five best qualities, the total frequency becomes 539 × $5=2,695$.

As displayed on the table above, the three most recognized (most frequently mentioned) qualities of a good project manager are the ability to share inspirational vision, good communication skill, and demonstrated competency. Accordingly, a competent project manager having properly communicated inspirational vision is very likely to be recognized as a good project manager.

This leads us to the study of the salient criteria for the nomination of project managers. Since there is no project management without project managers, the nomination of project managers to projects is an inevitable 
endeavor in project management. Thus, it is comprehensible that the unavoidable act of nominating a PM to a project should be supported with evidently preset objective nomination criteria. The nomination criterion not only helps company executives to assign the right project manager to the right project but also helps to avoid possible conflicts of interest among project team members and as a result ensures workplace harmony. Hence, maintaining explicit set of criteria for nominating project managers and communicating it to all concerned stakeholders makes the PM nomination process simple and straightforward. With this in mind, this study has identified a set of salient criteria to be considered by senior managers when nominating project managers to projects.

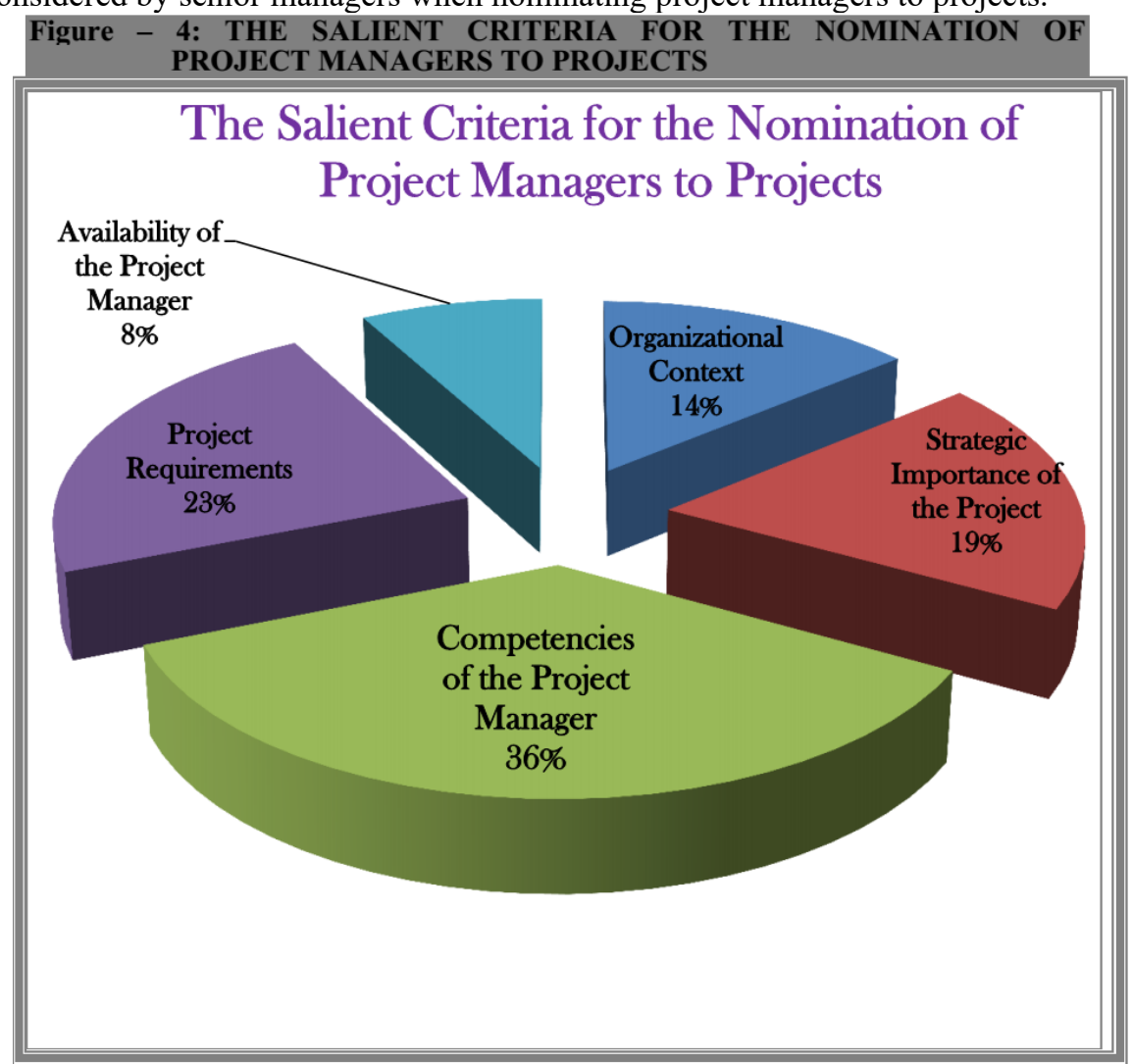

(Source: Own Survey)

As shown on the figure above, this research uncovered that the proper project manager assignment should include consideration of the organizational context, the strategic importance of the project, the competency of the project manager, the specific requirements of the project, and availability of the project manager (when the PM to be assigned is to manage more than one project simultaneously). Similarly, the research data also revealed that the assignment of a project manager cannot be complete without considering the correspondence between the competencies of the project manager and the project requirements, the bygone relationship (if any) between the company executives and the project manager, and the personal inclination of the project manager. Likewise, if the $\mathrm{PM}$ to be assigned is to manage multiple projects at the same time, the harmony and interdependency of the competing projects (such as resource requirements, Owner Company, complexity, duration, expected time of completion, etc.) must also be taken into account.

Given all the above PM nomination criteria, at which stage of the project life-cycle should a project manager be nominated was the next subject of investigation that this research attempted to address. 


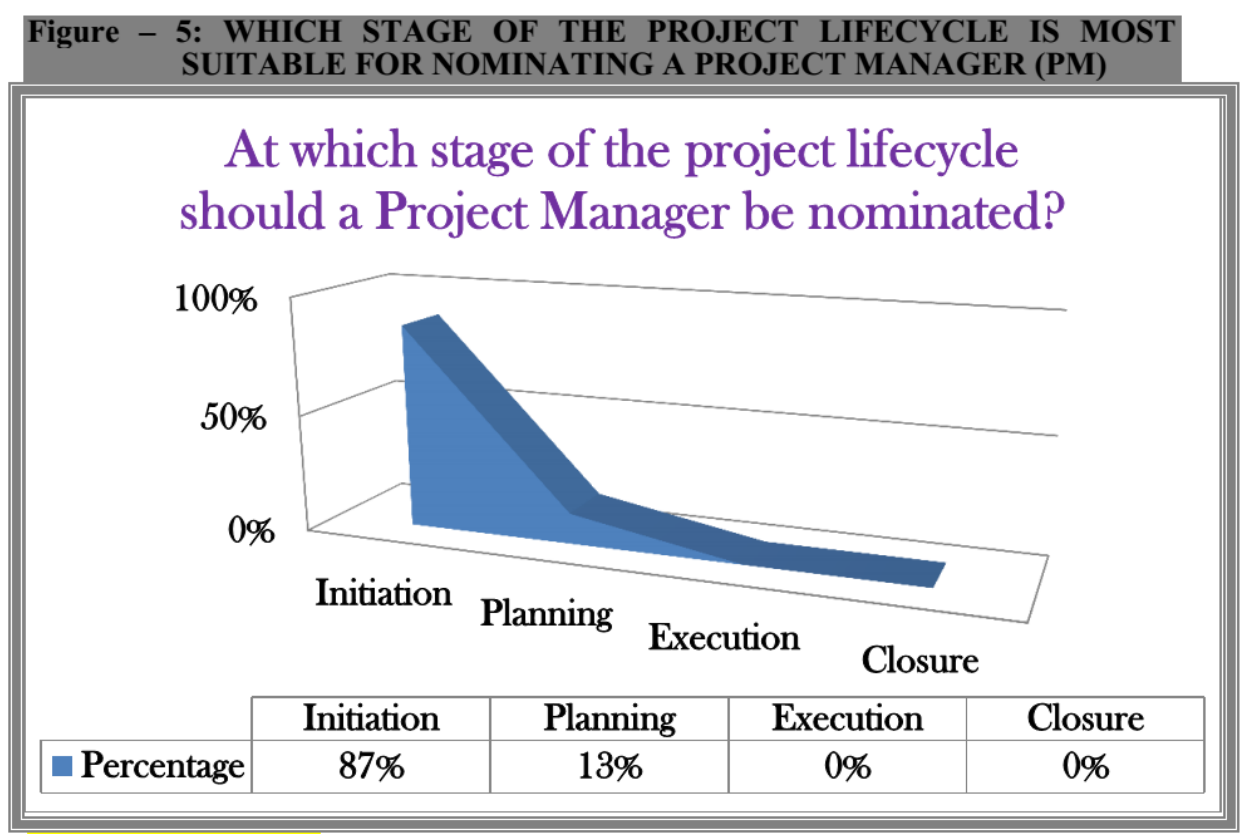

(Source: Own Survey)

All research participants, with no exception, declared that if assigning a project manager is deemed to be essential, the assignment should be done as early as possible. Accordingly, assigning a project manager before beginning to work on the project plan enables companies to get the best they can get from the PM than otherwise. This also helps the PM to shape the project in his/her own way and thereby own it. With no doubt, now the PM will be executing his/her own project plan for which he/she has a clear picture of how and where to go. Now, the project plan is his/her plan; and the company's vision is his/her vision. This, offers the PM the opportunity to create his/her own vision, to explore what the vision will mean to his/her job and live, and to envision his/her future as part of the vision of the owner company. In a perfect word, the PM is now in the best possible position to articulate the project plan to other project stakeholders and make them feel they have a real stake in the project. Further, this simplifies the job of the PM as he/she believes in the work he/she does, and he/she is fully vested in seeing the project from initiation. To make the matter more appealing, a PM involved from the very beginning of the project fully understands all project assumptions made (if any) and owns the work he/she does; and thus he/she will find it easy to convince senior management and influence decision making to get their help whenever needed.

At last, but most importantly, this research also investigated the importance of a PM to project success. Scott Berkun, the author of 'Making Things Happen', once said "A project manager is like a doctor who leads the trauma team and decides the course of action for a patient-both at the same time. Without the right kind of authority to efficiently handle all the project management issues, development teams can easily get into trouble." Accordingly, it is the project manager who primarily makes projects happen; and the project team is only as good as the project manager. Hence, a truly great PM is a strategic business partner fully vested in organizational success leading his/her team to the finish line successfully, now and in the future.

Moreover, the research data collected through focus group discussion with senior managers revealed that projects often fail when company executives fail to nominate the right project manager at the right time. As stated by these senior managers, the role of a PM in concluding projects successfully is supreme. Therefore, with the indisputable importance of project managers, it is worth to do whatever it takes to nominate the right PM as early as reasonably possible - before it becomes too late to fix problems. Altogether, a good PM is the true secret that brings projects to success. In brief, all research participants endorsed the importance of assigning project managers to projects without any sign of hesitation.

\section{9) Conclusion}

Because perception is a small thing that makes a big difference, the researcher of this study began his investigation by scrutinizing how the nomination of project managers to projects is perceived (both in principle and indeed) by project professionals. The findings revealed that, in principle, $91 \%$ of the respondents perceive the nomination of a PM as important decision in project management. But in effect only $66 \%$ of them perceive or consider the nomination of a PM as important decision. This shows that there is an outrageous gap between the theoretical and practical perceptions of project professionals to the nomination of a project manager.

The study also discovered the most important roles of project managers. Accordingly, monitoring project progress, executing the project plan, and implementing a project management methodology were picked as the first three core roles of a project manager by $21 \%, 17 \%$, and $11 \%$ of the respondents respectively. Yet all project 
managers are not equally able to play the roles expected of them. Therefore, to demonstrate their roles to the fullest, project managers need to have some qualities. In view of that, the ability to show the big picture or vision, communication skill, and competency were mentioned as the top three qualities of a good PM.

Taking everything into account, there is no doubt that the nomination of a PM should be merit based. For this effect, companies need to predetermine their PM nomination criteria - a standard on which a judgment or decision on PM nomination may be based. In the light of this, this research uncovered that the proper project manager assignment should include consideration of the organizational context, the strategic importance of the project, the competency of the project manager, the specific requirements of the project, and availability of the project manager (when the PM to be assigned is to manage multiple project simultaneously).

Since project managers are the key personnel of projects, premeditated nomination of project managers is of major importance to effective use of organization resources. The nomination criteria need to ensure that the PM to be nominated is able to bring strategic goals to reality. Anything less is a waste of scarce organizational resources - both human and nonhuman. Altogether, ensuring this requires a nomination process that is systematic, open, consistent, balanced, and above all, objective criteria based.

To sum up, an organization's effectiveness somewhat depends on the success of its projects. With this in mind, many efforts have been spent in recent decades to enhance the project management success. But results are still highly unsatisfactory, perhaps because the true problem is not yet identified - nomination of the wrong PM. In a project environment, everything seems to revolve about the project manager. The project manager is responsible for integrating assigned resources to complete the project according to plan. At the same time the PM needs to initiate changes in plans and schedules as persistent problems make plans unworkable. In other words, managers want to keep the project going while making necessary adjustments along the way.

Project managers must work with a diverse troupe of characters to complete projects. They are typically the direct link to the customer and must manage the tension between customer expectations and what is feasible and reasonable. Project managers also provide direction, coordination, and integration to the project team, which is often made up of part-time participants loyal to their functional departments. They often must work with a cadre of outsiders - vendors, suppliers, subcontractors - who do not necessarily share their project allegiance. These and many other accomplishments of project managers make them imperative instruments to conclude projects successfully. Hence, the importance of project managers is indisputable; and this is what this research proved.

Finally, the study also disclosed that the nomination of project managers should be made as early as possible. Early nomination of the PM has dual benefits - helps companies to make full use of the PM's expertise, and also enables the PM to design the project in his/her own way and own it.

\section{0) Recommendation}

This paper has taken a first step in researching a much-neglected problem in scholarly work on project management, namely the nomination of project managers to projects. Recommending further studies on the subject of this research in all possible settings, the researcher of this study recommends the following points for practitioners in the area.

2 Project professionals need to reconsider their practical perception towards the value they give to the process of PM nomination.

The nomination of a PM must be strategic and criteria based. Briefly, the researcher of this study recommends company executives to make sure that the organizational factors, the strategic importance of the project, the competencies of the project manager to be nominated, the project requirements, and the availability of the project manager are properly considered during the process of project manager nominations.

Finally, company executives ought to note that project managers should be nominated to projects as early as possible so as to enable companies to harvest the full benefits the PM.

\section{References}

$\checkmark$ Patanakul, Peerasit, and Dragan Z. Milosevic, "Assigning New Product Projects to Multiple-Project Managers: What Market Leaders Do,” Journal of High Technology Management Research, 17:1 (2006), pp. 53-69. 